\title{
LIFE CYCLE SUPPORT OF NAVY AIRBORNE ANTISUBMARINE WARFARE TACTICAL SOFTWARE
}

William R. Bogdan

Naval Air Development Center, Warminster, Pennsylvania surveillance.

\begin{abstract}
This paper deals with the process by which the Navy manages and provides engineering support throughout the life cycle of fleet ASW tactical software products. The discussion includes a description of the types of software products being supported and how Life Cycle Support (LCS) work is broken down and how resources are organized in order to provide functional improvements to the software during the long period it is operational in the fleet. Critical design factors are discussed that affect LCS costs and fleet delivery schedules. The kinds of management planning that is essential to fleet software maintenance are presented. The methodology the Navy uses to control changes to a software configuration baseline is addressed and how the Navy certifies software products prior to fleet release is also included. The paper concludes with a discussion on LCS cost estimating for the software.
\end{abstract}

\section{SECTION I. INTRODUCTION}

The purpose of this paper is to describe how the Navy manages and provides engineering support throughout the life cycle of Navy airborne Antisubmarine Warfare (ASW) tactical software. This paper addresses cradle-to-grave aspects of Life Cycle Support (LCS), but with particular emphasis on support requirements after the software becomes operational.

\section{SECTION 2. SOFTWARE DESCRIPTION}

Before going into the Navy's methodology for Life Cycle Support, the following provides a description of the software being supported. The software being discussed is one of the largest and most complex real time application software in existence today. Airborne ASW tactical software provides the control of electronic sensors and displays, computation of tactical and navigational algorithms, disposition and execution of ordnance and armaments, and the real time computer response to man-machine interface demands. These automated tasks are performed by the software for the purpose of accomplishing ASW mission requirements and tactically. pursuing targets of Navy interest.

Examples of this kind of airborne software are found in the Navy ASW platforms: P-3C, S-3A and LAMPS. P-3C is a long range, land-based patrol aircraft whose primary mission is antisubmarine warfare and ocean surveillance. The S-3A platform has a similar mission but is a carrier-based aircraft. LAMPS is a helicopter platform based aboard ships for the purpose of extending the range of a ship's sensor and weapon delivery capa- bilities. LAMPS' primary mission is ASW and anti-ship

ASW tactical software for a given platform is a large conglomerate of software. Less than one-third is used directly in the mission. The major share of this software is used for system test, system generation, simulation and training. In order to facilitate the Navy's management of this software complex, the software is divided into the following major systems:
a. Tactical Mission Software
b. System Test Software
c. Support Software
d. Trainer Software

Tactical Mission Software (TMS).

Tactical Mission Software provides the capability for processing, storing, correlating and displaying tactical data. This enables the crew officers and operators to optimize the utilization of ASW tactics and the platform equipment. Platform equipment consists of electronic sensor hardware such as acoustic signal analyzers, radar, infrared detection, electronic emission detection, and magnetic anomaly detection. Other equipment found on a platform is magnetic tape units, drum and disk storage, printers, keysets, CRTs, sonobuoy receivers, data link communication receivers/transmitters, and various types of navigation equipment such as inertial, doppler and Omega. TMS varies in size from 150-300K core words and is written for the most part in the Navy's high level languages, CS-1 and CMS-2. Note that ASW airborne platforms use military computers such as the CP-901, UYK-10 and AYK-14.

\section{System Test Software (STS).}

System Test Software provides system "Go-Nogo" tests which enable the crew members to verify operational readiness. In the event a fault is encountered during the "Go-Nogo" testing, the STS provides diagnostic software for fault isolation down to a hardware circuit board. STS varies in size from 200K-900K core words and is written in assembly language and CMS-2 high level language. Assembly language is used extensively to permit bit structures to be exercised and analyzed.

\section{Support Software.}

Support Software is resident on laboratory facility computers. 
This class of software is comprised of compilers, assemblers, loaders, system generators, simulation software, data reduction programs and utility routines.

\section{Trainer Software}

Trainer Software consists of platform simulation software and modifications of the Tactical Mission Software. It is resident on a replica of the tactical compartment of the aircraft and is used to train crew members to perform their particular operator functions and to perform as a cohesive unit.

\section{SECTION 3. LIFE CYCLE SUPPORT METHODOLOGY}

Navy Life Cycle Support (LCS) of software is an integrated cradle-to-grave process. This forces software developers to resolve, early in the software design stage, the requirements for fleet logistic support of the software. For the purpose of providing an orderly approach to the life support of software, the Navy divides LCS into three phases:

$$
\begin{aligned}
& \text { Phase } 1 \text { - Development } \\
& \text { Phase } 2 \text { - Transition } \\
& \text { Phase } 3 \text { - Navy Support }
\end{aligned}
$$

Development Phase

The Development Phase includes those activities which cover the requirements definition, design, code, debug, integration, and test of a new software system start. As part of the early planning for the software system, Navy agencies or commands are selected to assume responsibility for each LCS phase. The Development Activity (DA) assumes responsibility for the software's Phase 1 - Development. The Software Support Activity (SSA) assumes responsibility for Phase 3 - Navy Support. Both DA and SSA share responsibilities for Phase 2 - Transition.

\section{Transition Phase}

The Transition Phase includes a series of events that are directed toward the assumption of custody of the software by the fleet, and the development of the SSA capability to support the software. During this period the Navy conducts formal Test \& Evaluation in order to validate that the software will satisfy fleet operational requirements. At the same time, the SSA begins its build-up of personnel, establishment of facilities for software development and test, training of personnel, and assumption of the configuration management.

\section{Navy Support Phase}

The Navy Support Phase is the key to the Navy's ability for maintaining the readiness of its software in the face of changing threat conditions. This phase commences at the time the software is released to the fleet for operational use and remains in effect for the balance of the life of the software. During this phase, fleet users submit requests to the SSA for software modifications which result in periodic updates and re-issues of functionally improved software.

The Navy Support Phase minimizes the obsolescence of the ASW platform. Because these platforms are programmable, it is possible to recode portions of the software and create new functional capability. In their use of the platform, fleet operators and officers determine and suggest many unique functional improvements to the operation of the platform. Many of thesiz improvements can be implemented via the software or as a software work-around for a future hardware change. Periodically the Navy will make major hardware revisions and/or additions to a platform; however, these hardware updates do not occur frequently. Through periodic software re-issues (12-18 mos.) during the Navy Support Phase, the fleet can obtain significant s'stem improvements and thereby increase tactical proficiency in order to handle dynamic threat conditions.

\section{LCS Design Factors}

There are a number of software design factors that are critical to Life Cycle Support (LCS) that must be implemented in the initial development of the software. These factors are:

Top-down structured programming with standard constructs

High Level Language

Modular software architecture utilizing subroutines restricted to one function each

Consistent software interfaces/protocol

Standard documentation

Hardware monitoring equipment

Computer resource utilization analysis provisions

Hordware breakpoint monitoring capability

System data replay capability

Establishment of core and timing reserve

There is nothing new or innovative in this list. Navy experience indicates however that incorporating this set of factors in a software design can simplify the task of making changes to the software system after the software becomes operational

\section{LCS Planning Requirements and Controls}

The primary planning document the Navy requires for LCS of tactical software is the Software Life Cycle Mariagemerit Plan (SLCMP). The SLCMP is a high level document that addresses the question of how to put-it-all-together.

\section{SLCMP Vol 1:}

Sect 1.0 - States purpose; objective, and scope

Sect 2.0 - States applicable standards and instructions

Sect 3.0 - Identifies th software being managed

Sect 4.0 - Presents the life cycle schedule, milestones, potential risks, and contingency plans 
Sect 5.0 - Establishes who is in charge/responsible

Sect 6.0 - States how configuration management will be pursued

Sect 7.0 - Describes the QA provisions

Sect 8.0 - Defines how documentation will be processed

SLCMP Vol 2:

Shows resource requirements, funding, special agreements, detail procedures, facility descriptions, detail schedules.

Other key LCS documents which supplement the SLCMP are:

CM Plan

\section{QA Plan}

\section{Software Management Organization}

The software management organization begins with the Chief of Naval Operations who establishes overall objectives and provides funding. The Naval Air Systems Command is the Program Manager through the entire life cycle of the software. The software management organization also includes the Development Activity, the Software Support Activity, independent testing activity (for TECHEVAL and OPEVAL), and other interfacing ASW platforms.

Additionally, each platform has its own Software Change Review Board (SCRB) to assist the Program Manager in exercising configuration control of the software. The SCRB (consisting of the Program Manager, DA/SSA, and fleet users) reviews and evaluates proposed software changes to assess fleet operational impact and advise the Program Manager on the level of implementation priority that should be assigned to the changes. Note that the SCRB membership is required to include users of the software. As a result, the SCRB becomes the prime forum through which software users can make known their particular needs.

\section{Software Configuration Management (CM) Process}

The Navy considers configuration management as a vital and extensive process that must be omni-present through the life of the software. In general, the process is as follows:

a. The fleet or other Navy activities submit Program Trouble Reports (PTRs), Software Change Requests (SCRs), and Engineering Change Proposals (ECPs) for software corrections or new functional capabilities. Word of mouth or informal change requests are not recognized by the $\mathrm{CM}$ system.

b. The Software Change Review Board Secretariat formally receives, logs, acknowledges to the sender, and distributes the PTR, SCR, or ECPs to the Development Activity (DA) and/or Software Support Activity (SSA). c. The SSA or DA software engineers technically determine and document how correction or new functional capability will change the baseline (that is, which Configuration Item(s) will be changed).

d. The Software Change Review Board reviews the baseline thonges and recommends to the Program Manager an 昦

Iimplementation priority for each of the changes.

e. After receiving direction from the Program Manager on what changes to implement, the SSA or DA implements the approved changes and at the same time tracks the configuration baseline.

$f$. The TECHEVAL and OPEVAL activities through operational testing validate that the updated or new software baseline is in accordance with Program Manager approved changes and functional specifications.

g. The DA and SSA apprise the fleet of the functional capabilities of the new or modified software baseline upon delivery to the fleet.

\section{Automated Configuration Status Accounting}

In order to facilitate configuration management procedures, the Naval Air Development Center (NADC) as one of the Navy's cognizant DA and SSA uses automated Configuration Status ACcounting data bases. These data bases are resident on the NADC Computer System through the use of a commercial data base management system softwore package.

The automated data bases provide various formal periodic Configuration Status Accounting reports such as:

Configuration Identification List

Software Change Request/Program Trouble Report (SCR/PTR) Status

Engineering Change Proposal (ECP) Status

System Problem Report (SPR) Status

Software Change Notice (SCN) Reports

Additionally, the automated data bases are equipped with an "immediate access" feature which permits informal interrogation of the data base. Inquiries such as "List the SCR records impacting the Steering Module $(\mathrm{Cl}=\mathrm{nnn})$ with an implementation cost greater than $\$ 5000^{\prime \prime}$ can be easily and quickly made.

\section{Software QA Process}

The Navy places serious emphasis on its Quality Assurance (QA). This is demonstrated by considerable expenditure of funds in order to guarantee a high reliability for airborne ASW tactical software. The QA process relies on two features:

1. The software design is verified early in the development. Design problems surfaced early are less costly to correct in the initial software development stages. 
2. QA is performed by a team of engineers that is independent of the software development team. Since the QA team has no personal investment in the design and development of the software, it does not suffer from a lack of objectivity. The independent QA team performs its function with the firm belief that the software does contain errors that need to be determined and corrected.

The QA process begins with a number of software engineers and programmers laying-out design specifications for the development or modification of various software modules and/or programs. An independent QA team provides early verificotion by analyzing the design specifications through examination of functional descriptions, performance specifications, flow charts, interface protocol, etc. The QA team independently determines that the software design will satisfy the functional requirements. This early verification is completed before any code implementation.

After QA approval of the design, coding commences and is followed by three levels of testing: subprogram tests, program tests, and program integration tests. These tests are observed by the QA team. Upon completion of this testing, the coding effort is frozen and an interim program tape is delivered to the $Q A$ team who then perform independent laboratory functional and performance testing in order to validate that the software endproduct meets functional/performance requirements at the laboratory level.

After successful completion of the QA validation tests, the program development is frozen and formal Navy TECHEVAL commences and validates that the software is operational in an aircraft environment. If this is a major hardware update an OPEVAL will be conducted prior to fleet issue to determine that the updated platform is operationally satisfactory for fleet use. Successful completion of TECHEVAL and OPEVAL completes the QA process.

\section{Work Breakdown for Support of Airborne ASW Software}

The Navy uses a Work Breakdown Structure (WBS) to determine how the work is to be broken down into areas of effort. WBS is a management tool utilized in planning the progression of work, assigning responsibilities, and providing a framework for financial control and progress tracking. The major work breakdown categories for Phase 3 - Navy Support of airborne ASW tactical software are:

Project Management. Provide direction, plans, and schedules

Configuration Management. Provide configuration baseline control

Quality Assurance. Provide verification and validation

Software Production. Provide engineering analysis, design, code and debug

Laboratory Facilities. Provide operation and maintenance of software generation, integration, and training facilities

Similar breakdowns are used for software in Phase 1 - Develop- ment; however, the detail below the major categories woulc be significantly different in order to definitize specific requirements for the development of the new software. For additional information in Work Breakdown Structures, the reader is referred to Military Standard 881A. Although not shown here, the WES is usually presented in a hierarchial block diagram format.

\section{Staffing Strategy.}

This paper will now address how the Naval Air Developnent Center (NADC), as one of the Navy's principal developers of air ASW tactical software, organizes for its role as a cognizant Software Support Activity for given platform. The NADC is a matrix organization divided into a number of functional Directorates (that is, departments) and project management offices. This matrix organization provides technology research and engineering development for air systems of the Navy. In order to accomplish the fleet software support, personnel resources are dividecl into several formal and informal working groups:

Project Office

CM Team

$\begin{array}{ll}\text { QA Team } & \begin{array}{l}\text { TMS Team } \\ \text { Software Production }\end{array} \\ \text { Laboratory Operations } & \begin{array}{l}\text { STeam } \\ \text { Support Software Team } \\ \text { Trainer Software Team }\end{array}\end{array}$

Note that the grouping of the resources corresponds approximately to the Work Breakdown Structure. The Project Office is the management focal point for all the teams provided by the functional Directorates. Note that for Software Production there is a team for each of the software product lines. Each team has the responsibility for the analysis, design, code, debug, and integration for its assigned software product.

In an effort to provide dedicated and comprehensive engineering support for ASW software which is operational in the fleet, NADC has recently established the Fleet Software Engineering/Analysis Division within its Software and Computer Technology Directorate. The division is a group of 45 (and growing) so"tware engineers providing a complete line of software expertise required for fleet software support. This division provides engineering analysis, design, and implementation for tacticul mission software, system test software, and laboratory facility software products. Additionally, the division provides configuration management, product certification, $R \& D$ in software analysis aids, and R\&D in system test.

\section{Software Life Cycle Cost}

The foregoing discussion has reviewed the salient elements of Life Cycle Support of airborne ASW tactical software. Using this as a background, this paper will now address some of the aspects of the Naval Air Development Center's (NADC) afproach for determining the life cycle cost of airborne ASW tactical software. The costing technique used is largely a heuristic or intuitive approach. Note however that NADC is involved in a two year test and evaluation of the Department of Defenses's ADP Resource Estimating Procedures (REP). REP is a cetailed mathematical estimating procedure based upon the Norden/Rayleigh life cycle manpower curve. As results become 
available it is expected that NADC's procedures will be modified. For additional information on REP, the reader should write to Department of Defense Computer Institute, Washington Navy Yard, Washington, DC 20374.

In general, an experienced software planner or manager develops a Work Breakdown Structure as a basis for his life cycle cost estimates. The software Development and Transition phoses are broken down into a detailed sequence of activities such as requirements definition, design, documentation, coding, debug, integration, etc.; but with greater sub-detail in order to reflect actual software system architecture. Each one of the activities are then laid out on a milestone or schedule chart. The planner than assigns manning requirements for each activity bosed upon comparison against earlier similar software efforts. The sum of all the manning levels for each software activity then constitutes the total manpower resources required. Although hardware costing is outside the scope of this paper, similar procedures are followed for any hardware development related to the software system. Rough ranges of resources experienced to date for the Development, Transition, and Navy Support Phase of tactical software requiring 800-2400 manyears for life cycle support are:

$\begin{array}{lccc} & \text { PHASE 1 } & \text { PHASE } 2 & \text { PHASE } 3 \\ \text { MANYEARS/YR } & 60-100 & 120-240 & 40-80 \\ \text { DURATION } & 3-5 \mathrm{yrs} & 2-3 \mathrm{yrs} & 10-15 \mathrm{yrs} \\ \% \text { OF LIFE COST } & 25 \% & 25 \% & 50 \%\end{array}$

In determining life cycle cost for Phase 3 - Navy Support, the software planner or manager again develops a Work Breakdown Structure of activities and then schedules these activities through a fleet re-issue software cycle. In order to determine the manning requirement for each of the activities, the planner examines the extensiveness of the software, the demands and urgency for software change, and makes comparisons of manning levels to other similar software efforts. The following outlines the steps that are taken to determine rough order Phase 3 Navy Support life cycle costs:

1. Divide software into major systems, determine sizes and languages, and review complexity and maturity of major functions.

2. Estimate average number of requests per year and urgency for software change.

3. Develop a Work Breakdown Structure for each major software system and schedule work activities over a fleet re-issue cycle.

4. Determine manning requirement for each scheduled activity.

5. Convert staffing estimates to cost.

6. Add in nominal estimates for any equipment rental and material costs.

7. Sum items 5 and 6 to determine total re-issue cycle cost.

8. Estimate number of Phase 3 life re-issue cycles to determine total cost.

9. Adjust cycle cost by an inflation factor.
10. Decrease or taildown manning resources for last few cycles to provide manpower for next new software development.

11. Check total Navy Support Phase 3 cost by comparing to estimated sum of Development Phase 1 and Transition Phase 2 cost. Phase 3 should be approximately equal to the sum of Phase 1 and 2.

The above process is a moderately simple approach to Navy Support Phase 3 costing. Yearly budgets in actual use will fluctuate depending upon the urgency for software change in a given year. These fluctuations however are difficult to forecast. The best approach has been to determine a manning effort essentially based on software complexity, number of users, predetermined Work Breakdown Structure of activities, and a predicted schedule.

\section{Conclusion.}

A descriptive overview of Navy life Cycle Support of airborne ASW tactical software has been provided. Because of the multimillion dollar cost of fleet software logistics, the LCS process is under continual scrutiny by Navy management and as a consequence, the process will change as new LCS methodology is developed by the Government and private industry. The Government has developed numerous military standards and instructions which are the basis and guidelines for the current LCS methodology in this paper. The reader seeking more detailed information is referred to NAVAIR Instruction 5230.5. This document, in addition to defining the requirements for generation of the Navy Software Life Cycle Management Plan (SLCMP), contains a list of applicable standards, specifications, and instructions. 